\title{
Erratum to: Reverse shoulder arthroplasty in acute fractures provides better results than in revision procedures for fracture sequelae
}

Nikola Cicak $\cdot$ Hrvoje Klobucar $•$ Nenad Medancic

Published online: 11 January 2015

(C) SICOT aisbl 2015

Erratum to: International Orthopaedics (SICOT)

DOI: 10.1007/s00264-014-2649-7

The original publication of this article inadvertently contained a mistake in the presentation of the name of the authors.

The correct presentation is given above.

The online version of the original article can be found at http://dx.doi.org/ 10.1007/s00264-014-2649-7.

N. Cicak $(\varangle) \cdot$ H. Klobucar $\cdot$ N. Medancic

Special Hospital for Orthopaedic Surgery, AKROMION, Krapinske

Toplice, Croatia

e-mail: nikcicak@yahoo.com 